\title{
A Prospective Follow up of Metabolic Changes among Obese Women using two Different Regimens of Ethinylestradiol/ Drospirenone Containing Contraceptive Pills
}

\author{
Mohamed Emarh, MD*, Ragab Dawood, MD \\ Department of Obstetrics and Gynecology, Faculty of Medicine, Menoufia University, Menoufia, Egypt \\ *Corresponding Author: Mohamed Emarh, Department of Obstetrics and Gynecology, Faculty of \\ Medicine, Menoufia University, Menoufia, Egypt, Email: mohemarh@yahoo.com
}

\begin{abstract}
Objectives: To assess metabolic changes among obese women using 21/7 regimen Ethinylestradiol (EE) 30 ug/Drospirenone (DRSP) $3 \mathrm{mg}$ compared to 24/4 regimen EE $20 \mathrm{ug} /$ DRSP $3 \mathrm{mg}$ over 24 months of use.

Methods: Obese women (Body mass index $\geq 30$ ) who desired Combined oral contraceptive pills (COCs) were designated for two groups; group 1(n=94): 21/7 regimen Ethinylestradiol (EE) 30 ug/ Drospirenone (DRSP) $3 \mathrm{mg}$ one tablet daily for 21 days with 7 days off and group 2 ( $n=92):$ 24/4 regimen EE 20 ug/ DRSP $3 \mathrm{mg}$ one tablet daily for 24 days followed by a 4-day placebo period. Metabolic changes after 12 and 24 cycles of use was the main outcome measure.
\end{abstract}

Results: There was no significant difference between the two groups regarding body weight, waist circumference, blood pressure, fasting blood glucose, triglycerides and LDL cholesterol with significant decline in total cholesterol levels after 12 cycles $(p<0.05)$ and 24 cycles $(p<0.001)$ from baseline levels in both groups. Also, HDL cholesterol was significantly increased after 12 cycles $(p<0.05)$ and 24 cycles ( $p<0.001)$ from baseline levels in both groups.

Conclusion: DRSP containing COCs do not induce detrimental metabolic changes and have favorable lipid profile among obese women when used for 12-24 cycles.

Keywords: Ethinylestradiol/drospirenone, blood lipids, obese women.

\section{INTRODUCTION}

Combined oral contraceptives (COC) are a wellestablished method of contraception with proven safety and efficacy for many decades [1]. New low-dose oral contraceptives containing drospirenone have few health risks and many health benefits as drospirenone has an antimineralocorticoid and a slightly anti-androgenic action $[2,3]$.

The aim of this study was to assess metabolic changes among obese women using 21/7 regimen Ethinylestradiol (EE) $30 \mathrm{ug} /$ Drospirenone (DRSP) 3mg compared to 24/4 regimen EE 20 ug/ DRSP 3mg over 24 months of use.

\section{MATERIALS AND METHODS}

This prospective comparative study was conducted at departments of Obstetrics \& Gynecology, in Menoufia University hospital, Menoufia governorate, Egypt; between the beginnings of August 2017 and September 2019.
Before initiating the study, the local ethical review board approved the study protocol with all included participants signed the informed consent form, after thorough explanation of the study objectives.

Based on previous publication [4], 90 women in each group were needed in each group to detect a $10 \%$ significant change of metabolic criteria over 12 cycles of use according to $20 \%$ type II error with power set at $80 \%$.

Healthy obese women with body mass index above $30 \mathrm{Kg} / \mathrm{m}^{2}$ between the ages of 20 and 35 who requested oral contraceptive therapy, who had no medical contraindication to $\mathrm{COCs}$ therapy were invited to participate.

All included women neither were smokers, having criteria used for diagnosing the metabolic syndrome [5] nor, had used herbal remedies or blood lipid-lowering agents for weight reduction during the whole duration of the study. Participants were divided into two 
groups based on their choices regarding COCs regimen:

Group 1(n=94): 21/7 regimen Ethinylestradiol $30 \mathrm{ug} /$ Drospirenone 3mg (Yasmin, Bayer Pharma AG, Berlin, Germany). One tablet daily for 21 days with 7 days off

Group 2 (n=92): 24/4 regimen Ethinylestradiol 20 ug/ Drospirenone 3mg (Yaz, Bayer Healthcare Pharmaceuticals Inc. Berlin, Germany).

Each treatment cycle consisted of 24 consecutive days of active treatment followed by a 4-day placebo period.

All women included in the study underwent:

- Clinical examination: body weight, height, waist circumference (WC) and blood pressure measurements. WC was taken midway between the lowest rib margin and the iliac crest.

- -Laboratory testing: following overnight fast, baseline investigations in the form of fasting blood glucose (FBG) and fasting blood lipid profile (Triglycerides, total cholesterol, high density lipoprotein (HDL) cholesterol and low-density lipoprotein (LDL) cholesterol) were measured.

- $\quad$-Follow up in the outpatient clinic monthly during the first 6 months of use then bimonthly for the next 18 months.

- -Clinical examination and laboratory testing were repeated at 12 and 24 cycles.

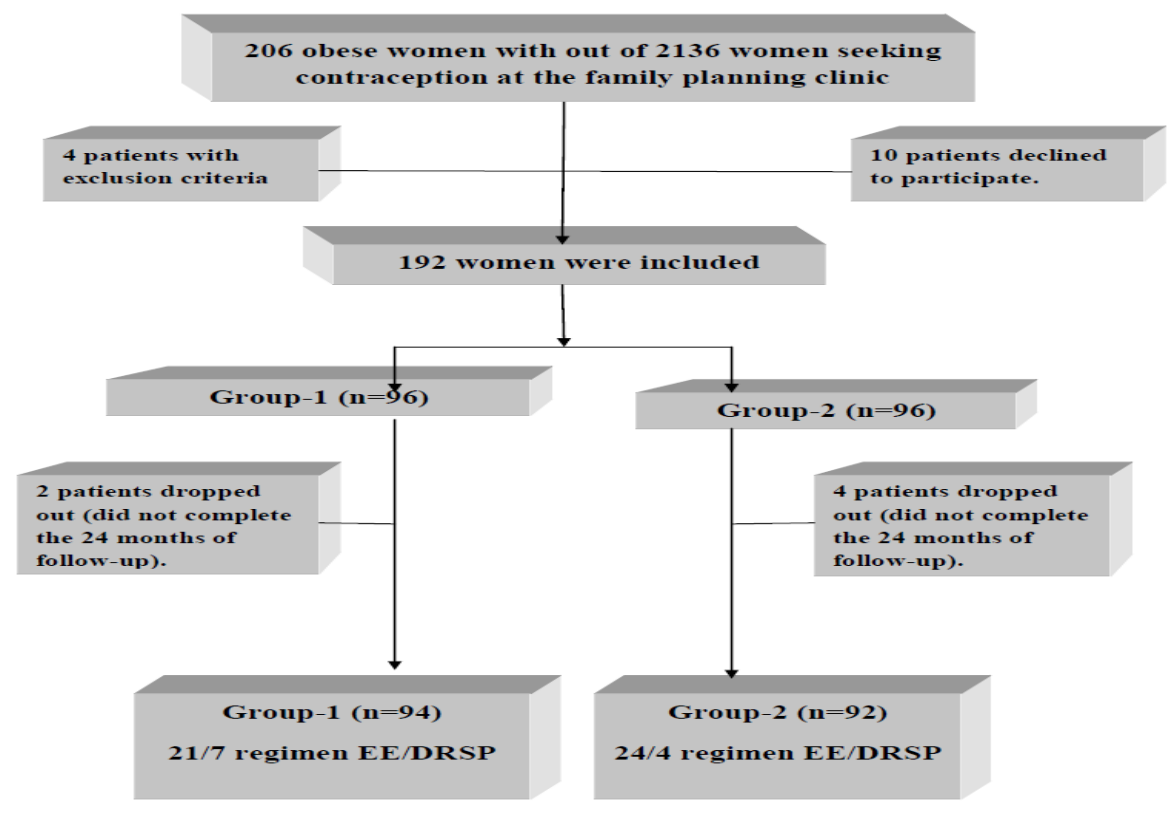

Figure1. Flow diagram of recruitment and retention of participants in the study

\section{OUTCOME MeAsures}

- The primary outcome was to measure metabolic changes.

- The secondary outcomes included adverse effects and women acceptability.

Adverse effects were recorded during follow up visits as participants were asked to do so while women acceptability was assessed via questionnaire at the end of 24 cycles of treatment (in terms of overall discomfort, overall satisfaction and advisability of the method to other women).

\section{STATISTICAL ANALYSIS}

Statistical analysis was performed using Statistical Package for the Social Sciences Version 20 (IBM Corp., Armonk, NY, USA).
Chi square test and Student's t-test were used as appropriate. $\mathrm{P}<0.05$ was considered to be significant.

\section{ReSUlts}

The study was started with 96 participants in each group but 2 participants in group 1 and 4 participants in group 2 did not complete the 24 cycles of treatment and not included in the final analysis of data Participants' age in years was $(26.4 \pm 6.3$ vs $26.6 \pm 6.1)$ and body mass index in $\mathrm{Kg} / \mathrm{m}^{2}$ was $(33.3 \pm 2.1$ vs $33.2 \pm 2.1)$ respectively.

There was no significant difference between the two groups regarding baseline body weight (BW, $\mathrm{Kg}$ ), BW after 12 cycles, BW after 24 cycles, baseline Waist circumference (WC, $\mathrm{cm}$ ), WC after 12 cycles, WC after 24 cycles, baseline systolic blood pressure (SBP, mmHg), SBP after 
A Prospective Follow Up of Metabolic Changes among Obese Women Using Two Different Regimens of Ethinylestradiol/Drospirenone Containing Contraceptive Pills

12 cycles, SBP after 24 cycles, baseline diastolic blood pressure (DBP, mmHg), DBP after 12 cycles and DBP after 24 cycles as shown in table 1

Table1. Changes in body weight, waist circumference and arterial blood pressure after 12 and 24 cycles in comparison to baseline characteristics

\begin{tabular}{|c|c|c|c|c|}
\hline & Group-1 (n=94) & Group-2 (n=92) & Student t-test & P-value \\
\hline $\begin{array}{l}\text { Body weight }(\mathbf{K g}) \\
\text {-Basal } \\
\text { After } 12 \text { cycles } \\
\text { (compared to basal) } \\
\text {-After } 24 \text { cycles } \\
\text { (compared to basal) }\end{array}$ & $\begin{array}{l}88.8 \pm 7.2 \\
88.3 \pm 7.3 \\
(P>0.05) \\
88.1 \pm 7.2 \\
(P>0.05)\end{array}$ & $\begin{array}{l}88.2 \pm 7.9 \\
88.1 \pm 7.6 \\
(P>0.05) \\
88.1 \pm 7.5 \\
(P>0.05)\end{array}$ & $\begin{array}{l}0.54 \\
0.18 \\
0.99\end{array}$ & $\begin{array}{l}>0.05 \\
>0.05 \\
>0.05\end{array}$ \\
\hline $\begin{array}{l}\text { Waist circumference (cm) } \\
\text {-Basal } \\
\text { After } 12 \text { cycles } \\
\text { (compared to basal) } \\
\text {-After } 24 \text { cycles } \\
\text { (compared to basal) }\end{array}$ & $\begin{array}{l}77.1 \pm 5.3 \\
76.9 \pm 5.3 \\
(P>0.05) \\
76.6 \pm 5.1 \\
(P>0.05)\end{array}$ & $\begin{array}{l}77.3 \pm 5.1 \\
77.1 \pm 5.2 \\
(P>0.05) \\
76.9 \pm 5.1 \\
(P>0.05)\end{array}$ & $\begin{array}{l}0.26 \\
0.27 \\
0.40\end{array}$ & $\begin{array}{l}>0.05 \\
>0.05 \\
>0.05\end{array}$ \\
\hline $\begin{array}{l}\text { Arterial blood pressure (mmHg) } \\
\text {-Basal systolic } \\
\text { After } 12 \text { cycles } \\
\text { (compared to basal) } \\
\text {-After } 24 \text { cycles } \\
\text { (compared to basal) }\end{array}$ & $\begin{array}{l}118.5 \pm 6.5 \quad 117.9 \pm 5.9 \\
(P>0.05) \\
117.8 \pm 5.3 \\
(P>0.05)\end{array}$ & $\begin{array}{l}118.3 \pm 6.7 \\
117.4 \pm 6.1 \\
(P>0.05) \\
117.9 \pm 5.1 \\
(P>0.05)\end{array}$ & $\begin{array}{l}0.21 \\
0.57 \\
0.13\end{array}$ & $\begin{array}{l}>0.05 \\
>0.05 \\
>0.05\end{array}$ \\
\hline $\begin{array}{l}\text {-Basal diastolic } \\
\text { After } 12 \text { cycles } \\
\text { (compared to basal) } \\
\text {-After } 24 \text { cycles } \\
\text { (compared to basal) } \\
\end{array}$ & $\begin{array}{l}72.7 \pm 5.2 \\
72.6 \pm 5.1 \\
(P>0.05) \\
72.5 \pm 4.9 \\
(P>0.05)\end{array}$ & $\begin{array}{l}72.6 \pm 5.3 \\
72.7 \pm 5.2 \\
(P>0.05) \\
72.6 \pm 4.8 \\
(P>0.05)\end{array}$ & $\begin{array}{l}0.13 \\
0.13 \\
0.12\end{array}$ & $\begin{array}{l}>0.05 \\
>0.05 \\
>0.05\end{array}$ \\
\hline
\end{tabular}

No significant change was observed between the two groups $(p>0.05)$ or from baseline values ( $>0.05)$ regarding fasting blood glucose, triglycerides and LDL cholesterol with significant decline in total cholesterol levels after 12 cycles $(\mathrm{p}<0.05)$ and 24 cycles $(\mathrm{p}<0.001)$ from baseline levels in both groups.

Also, HDL cholesterol was significantly increased after 12 cycles $(\mathrm{p}<0.05)$ and 24 cycles $(p<0.001)$ from baseline levels in both groups as depicted in table 2

Table2. Changes in fasting blood glucose and fasting blood lipids after 12 and 24 cycles in comparison to baseline characteristics

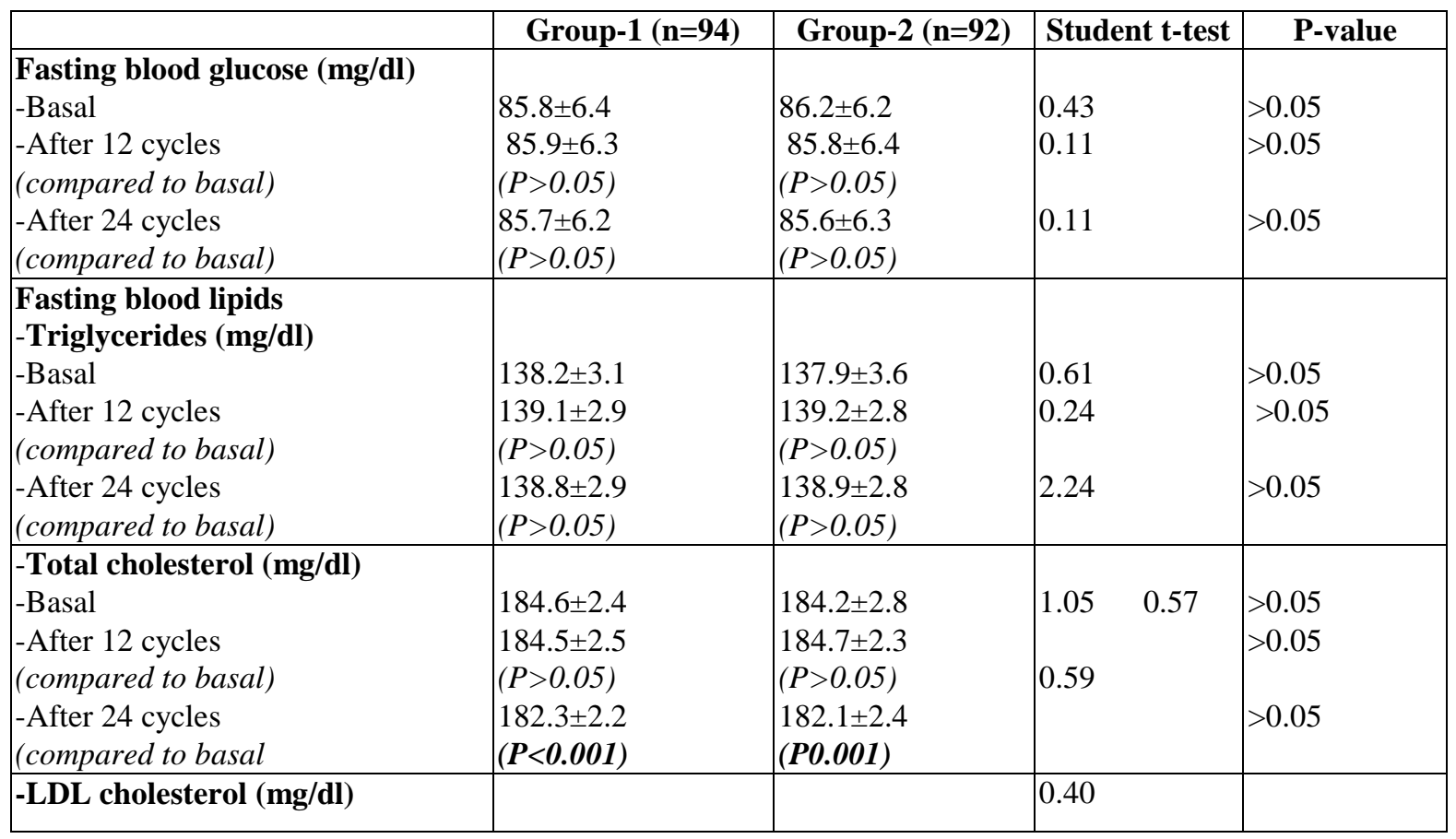


A Prospective Follow Up of Metabolic Changes among Obese Women Using Two Different Regimens of Ethinylestradiol/Drospirenone Containing Contraceptive Pills

\begin{tabular}{|c|c|c|c|c|}
\hline \begin{tabular}{|l|}
-Basal \\
-After 12 cycles \\
(compared to basal) \\
-After 24 cycles \\
(compared to basal) \\
\end{tabular} & $\begin{array}{l}121.7 \pm 3.3 \\
121.5 \pm 3.2 \\
(P>0.05) \\
121.2 \pm 3.1 \\
(P>0.05)\end{array}$ & $\begin{array}{l}121.5 \pm 3.5 \\
121.4 \pm 3.3 \\
(P>0.05) \\
121.4 \pm 3.1 \\
(\mathrm{P}>0.05)\end{array}$ & $\begin{array}{l}0.21 \\
0.44\end{array}$ & $\begin{array}{l}>0.05 \\
>0.05 \\
>0.05\end{array}$ \\
\hline $\begin{array}{l}\text {-HDL cholesterol (mg/dl) } \\
\text {-Basal } \\
\text {-After } 12 \text { cycles } \\
\text { (compared to basal) } \\
\text {-After } 24 \text { cycles } \\
\text { (compared to basal) } \\
\end{array}$ & $\begin{array}{l}57.2 \pm 3.2 \\
58.3 \pm 3.7 \\
(\boldsymbol{P}<0.05) \\
59.7 \pm 4.3 \\
(\boldsymbol{P}<0.001)\end{array}$ & $\begin{array}{l}57.3 \pm 3.1 \\
58.6 \pm 3.4 \\
(\boldsymbol{P}<\boldsymbol{0 . 0 5 )} \\
59.5 \pm 4.5 \\
(\boldsymbol{P}<\boldsymbol{0 . 0 0 1 )}\end{array}$ & $\begin{array}{l}0.22 \\
0.58 \\
0.31\end{array}$ & $\begin{array}{l}>0.05 \\
>0.05 \\
>0.05\end{array}$ \\
\hline
\end{tabular}

Table3. Adverse effects and acceptability of the methods used

\begin{tabular}{|l|l|l|l|l|}
\hline & Group-1 (n=94) & Group-2 (n=92) & Chi square test & P-value \\
\hline Headache & 12 & 14 & 0.07 & $>0.05$ \\
\hline Nausea & 6 & 8 & 0.10 & $>0.05$ \\
\hline Menstrual changes & 14 & 10 & 0.36 & $>0.05$ \\
\hline Mood changes & 3 & 3 & 0.15 & $>0.05$ \\
\hline Vaginal discharge & 8 & 14 & 1.41 & $>0.05$ \\
\hline Lower abdominal pain & 8 & 6 & 0.06 & $>0.05$ \\
\hline Venous thromboembolism & 0 & 0 & - & - \\
\hline $\begin{array}{l}\text { Overall discomfort with the method: } \\
\text {-Moderate/High/Extreme } \\
\text {-None or slight }\end{array}$ & 4 & 5 & 0.01 & $>0.05$ \\
\hline $\begin{array}{l}\text { Overall satisfaction with the method: } \\
\text {-Very or somewhat satisfied } \\
\text {-Neutral or somewhat not satisfied }\end{array}$ & 90 & 87 & 0.01 & $>0.05$ \\
\hline $\begin{array}{l}\text { Would recommend the method to } \\
\text { other women: } \\
\text {-Highly or somewhat agree } \\
\text {-Neutral or somewhat disagree }\end{array}$ & 3 & 90 & 0.23 & $>0.05$ \\
\hline
\end{tabular}

\section{DISCUSSION}

The current study revealed absence of any significant change in the body weight, blood pressure and fasting blood glucose among obese women after 24 cycles of use of two different formulations and two different regimens of EE/DRSP COCs.

Absence of any change in body weight and blood pressure following the use of EE/DRSP COCs was reported by previous studies over 6-36 cycles of use $[4,6,7]$ even in hypertensive patients [8].

A previous randomized trial including 72 women reported that the EE/DRSP preparation demonstrated a more favorable effect on body mass index (BMI) and blood pressure (BP) with the mean BMI and mean BP remaining lower than baseline mean after 6-12 cycles of use [9].

Drospirenone (DRSP) is $17 \alpha$-spirolactone derivative, acting as an antagonist of aldosterone receptors with clinically recognized ant androgenic and anti-mineralocorticoid activity

ARC Journal of Gynecology and Obstetrics in addition to its potent progestogenic activity, may reduce possible water retention in women using COCs which is the main responsible factor in stabilizing or even decreasing the blood pressure among users $[10,11]$.

In this study, no significant change was observed in triglycerides (TG) levels after 12-24 cycles of use among obese women.

Previous studies reported contradictory findings regarding changes in TG levels with the use of EE/DRSP COCs, some reported absence of significant changes at 12 cycles of use [7], increase in TG levels after 6 cycles in hypertensive patients [8], after 13 cycles [6] or after 24-36 cycles of use [4].

However, this increase still lies within the normal range for TG in women in addition to different populations studied. In contrast to endogenous hypertriglyceridemia, there is good evidence that elevated triglycerides secondary to COCs use do not increase the atherosclerotic risk if HDL levels are also high $[12,13]$ and LDL is not increased. In the current study, HDL 
cholesterol was significantly increased after 12 and 24 cycles from baseline levels.

This was reported by previous studies after variable cycles of use [4, 6-8]. Alterations in serum lipids during COCs intake depend on the EE dose and both the type and dose of (whether anti-androgenic activity is marked or absent).

Both EE and progestogen have counteracting effects on serum lipids. Progestogens with androgenic activity can shift lipid and lipoprotein metabolism in a potentially unfavorable way $[14$, $15]$.

Drospirenone-containing COCs displays a potentially favorable change in lipid profile with increased HDL/LDL ratio which is considered clinically beneficial with respect to cardiovascular disease risk [6].

In the current study, there was no difference between both groups regarding adverse effects particularly bleeding patterns and patients' acceptability as most adverse effects were transient and mild without the need for specific interventions or method withdrawal.

A previous large study conducted on 326 healthy women (received EE 30ug/DRSP $3 \mathrm{mg}$ in 21/7 regimen) compared to 1027 healthy women (received EE 20ug/DRSP $3 \mathrm{mg}$ in 24/4 regimen); found no significant difference in cycle regularity and bleeding disorders between the two regimens of EE/DRSP COCs [16].

The strength of this study resides in being prospective with inclusion of high risk group (obese women) for cardiovascular disease.

Inability to conduct a randomized trial and to include a larger group of women as well as to record diet preferences of participants throughout the follow up period; was unintended limitations of the current study.

Future research should explore the impact of using EE/DRSP COCs on women with different risk factors for cardiovascular diseases as smoking and prior history of hypertension.

\section{CONClusion}

DRSP containing COCs do not induce detrimental metabolic changes and have favorable lipid profile among obese women when used for 12-24 cycles.

\section{REFERENCES}

[1] Practice Committee of the American Society for Reproductive Medicine Hormonal contraception: recent advances and controversies. Fertil Steril 2008;90(3):103-13

[2] Sitruk-Ware R, Nath A. The use of newer progestins for contraception Contraception 2010; 82:410-7.

[3] Trussell J. Contraceptive failure in the United States. Contraception 2011;:404-83:397

[4] Rezk M, Sayyed T, Ellakwa H, et al. Metabolic changes in overweight and obese women above 35 years using Ethinylestradiol /drosperinone combined contraceptive pills: a 3-year casecontrol study. Gynecol Endocrinol. 2016; 32(10):844-847.

[5] Grundy SM, Cleeman JI, Daniels SR, et al. Diagnosis and management of the metabolic syndrome: an American heart association/natio nnal heart, lung, and blood institute scientific statement. Circulation 2005; 112:2735-52.

[6] Gaspard U, Endrikat J, Desager JP, et al. randomized study on the influence of oral contraceptives containing ethinylestradiol combined with drospirenone or desogestrel on lipid and lipoprotein metabolism over a period of 13 cycles. Contraception. 2004; 69(4):271-8.

[7] Mohamed AM, El-Sherbiny WS, Mostafa WA. Combined contraceptive ring versus combined oral contraceptive $(30-\mu \mathrm{g}$ ethinylestradiol and 3-mg drospirenone). Int $\mathbf{J}$ Gynaecol Obstet. 2011; 114(2):145-8.

[8] de Morais TL, Giribela C, Nisenbaum MG, et al. Effects of a contraceptive containing drospirenone and ethinylestradiol on blood pressure, metabolic profile and neurohumoral axis in hypertensive women at reproductive age. Eur J Obstet Gynecol Reprod Biol. 2014; 182:113-7.

[9] Yildizhan R, Yildizhan B, Adali E, et al. Effects of two combined oral contraceptives containing ethinyl estradiol 30 microg combined with either gestodene or drospirenone on hemostatic parameters, lipid profiles and blood pressure. Arch Gynecol Obstet. 2009; 280(2):255-61.

[10] Oelkers W, Drospirenone. A progestogen with antimineralocorticoid properties: a short review. Mol Cell Endocrinol 2004; 217(12):255-61.

[11] Foidart JM. Added benefits of drospirenone for compliance. Climacteric 2005; 8(3):28-34.

[12] Castelli WP. The triglyceride issue: a view from Framingham. Am Heart J 1986; 112:432-7.

[13] NIH Consensus Development Panel on Triglyceride, High Density Lipoprotein and 
A Prospective Follow Up of Metabolic Changes among Obese Women Using Two Different Regimens of Ethinylestradiol/Drospirenone Containing Contraceptive Pills

Coronary Heart Disease. JAMA 1993; 269:50510.

[14] Crook D, Godsland I. Safety of modern oral contraceptives. Contraception; 1998; 57:189201.

[15] Nofer JR, Kehrel B, Folker M, et al.. HDL and arteriosclerosis: beyond reverse cholesterol transport Atherosclerosis 2002; 161:1-16.
[16] Marr J1, Gerlinger C, Kunz M. A historical cycle control comparison of two drospirenonecontaining combined oral contraceptives: ethinylestradiol $30 \mu \mathrm{g} /$ drospirenone $3 \mathrm{mg}$ administered in a $21 / 7$ regimen versus ethinylestradiol $20 \mu \mathrm{g} /$ drospirenone $3 \mathrm{mg}$ administered in a 24/4 regimen. Eur J Obstet Gynecol Reprod Biol. 2012 May; 162(1):91-5.

Citation: Mohamed Emarh, Ragab Dawood. A Prospective Follow Up of Metabolic Changes among Obese Women Using Two Different Regimens of Ethinylestradiol/Drospirenone Containing Contraceptive Pills. ARC Journal of Gynecology and Obstetrics. 2019; 4(2): 27-32. DOI:dx.doi.org/10.20431/2456-0561.0402004.

Copyright: (C) 2019 Authors. This is an open-access article distributed under the terms of the Creative Commons Attribution License, which permits unrestricted use, distribution, and reproduction in any medium, provided the original author and source are credited. 